\title{
Regional Analgesia Technique for Post-Thoracotomy Pain
}

\author{
Tuhin Mistry ${ }^{1}$ (D)
}

Received: 4 August 2019 / Accepted: 3 January 2020 / Published online: 11 January 2020

(C) Indian Association of Surgical Oncology 2020

I read the recently published case series in Indian Journal of Surgical Oncology on "Serratus Anterior Plane Block for Post-Thoracotomy Analgesia: A Novel Technique for the Surgeon and Anaesthetist" by Vig et al. with interest [1]. I would like to congratulate and thank the authors for sharing their research work. However, it is important to note some aspects about analgesia in thoracotomy:

1. Authors have mentioned serratus anterior plane block (SAPB) for post-thoracotomy analgesia as a 'novel' technique, which is not appropriate. Okmen et al. used continuous SAPB for management of thoracotomy pain [2].

2. SAPB has also been compared with thoracic epidural analgesia (TEA) and thoracic paravertebral block (TPVB). It was found to be a safe alternative, provides adequate analgesia comparable to TEA [3] and TPVB [4], and decreases the perioperative opioid consumption.

3. According to the authors, four out of 10 patients (40\%) required intravenous fentanyl infusion in spite of continuous SAPB $(5-7 \mathrm{ml} / \mathrm{h})$ with $0.125 \%$ ropivacaine with fentanyl $(1 \mathrm{mcg} / \mathrm{h})$. Considering the severity of postthoracotomy pain, the concentration of ropivacaine infusion was suboptimal. It would have been better controlled if the concentration were $\geq 0.2 \%$. Hence, preemptive use of regional analgesia along with multimodal analgesia and/or additional drain site infiltration would offer better pain management in patients undergoing thoracotomy.

4. Recently, Tulgar et al. [5] described ultrasound-guided single and bi-level erector spinae plane block (ESPB) for postoperative analgesia in thoracotomy. ESPB is a promising regional analgesic technique which can be performed away from the surgical site and provide good analgesia to hemithorax. However, prospective randomised clinical trial comparing with other techniques is warranted.

\section{References}

1. Vig S, Bhan S, Ahuja D et al (2019) Serratus anterior plane block for post-thoracotomy analgesia: a novel technique for the surgeon and anaesthetist. Indian J Surg Oncol. https://doi.org/10.1007/s13193019-00937-2

2. Okmen K, Okmen BM, Uysal S (2016 Jul) Serratus anterior plane (SAP) block used for thoracotomy analgesia: a case report. Korean J Pain 29(3):189-192

3. Khalil AE, Abdallah NM, Bashandy GM, Kaddah TA (2017 Feb) Ultrasound-guided serratus anterior plane block versus thoracic epidural analgesia for thoracotomy pain. J Cardiothorac Vasc Anesth 31(1):152-158

4. Saad FS, El Baradie SY, Abdel Aliem MAW, Ali MM, Kotb TAM (2018 Oct-Dec) Ultrasound-guided serratus anterior plane block versus thoracic paravertebral block for perioperative analgesia in thoracotomy. Saudi J Anaesth 12(4):565-570

5. Tulgar S, Selvi O, Ozer Z (2018 Nov) Clinical experience of ultrasound-guided single and bi-level erector spinae plane block for postoperative analgesia in patients undergoing thoracotomy. J Clin Anesth 50:22-23

Publisher's Note Springer Nature remains neutral with regard to jurisdictional claims in published maps and institutional affiliations.

Tuhin Mistry

dr.tuhin2014@gmail.com

1 Department of Anaesthesiology, Critical Care and Pain \& Palliative Care, All India Institute of Medical Sciences, Raipur, Chhattisgarh, India 